\title{
SITES OF ANALGESIC ACTION OF CIRAMADOL
}

\author{
Atsuhiko KUBOTA, Masamichi SATOH and Hiroshi TAKAGI \\ Department of Pharmacology. Faculty of Pharmaceutical Sciences. \\ Kyoto University, Sakyo-ku, Kyoto 606, Japan
}

Accepted July 7, 1983

Ciramodol, a benzylamine derivative [ 1 cis-2-(dimethyl-amino-3'-hydroxy-phenylmethyl)cyclohexanol], has been reported to be an agonist-antagonist analgesic drug in animals (1) and humans (2). However, the profiles and sites of analgesic action of the drug in animals have not yet been shown.

Satoh et al. (3) have demonstrated that the flexor reflex induced by intra-arterial injection of bradykinin in the rat was an objective and sensitive index for evaluating various analgesic drugs. Pentazocine and cyclazocine were shown to produce analgesic effects in the bradykinin-induced flexor reflex test (4), though the drugs did not elicit antinociceptive effects without marked impairment in the tail-pinch, tail-flick and notplate methods.

In the present experiments, antinociceptive effects of ciramadol were evaluated using three analgesic tests: the tail-pinch, hot-plate and bradykinin-induced flexor reflex tests. Further, in order to search for the sites of analgesic action of ciramadol in rats, the drug was not only administered systemically, but also applied locally to the lumbar subarachnoid space and nuclei reticularis paragigantocellularis and gigantocellularis (NRPG-NRGC), which are sensitive sites to morphine in the production of anaigesia $(5,6)$

The tail-pinch tests were performed in male dd-K mice ( $14-17 \mathrm{~g})$ and SpragueDawley rats $(180-200 \mathrm{~g})$ according to the method described by Takagi et al. (7) and Akaike et al. (8), respectively.

The hot-plate tests were done using male dd- $K$ mice $(22-26 \mathrm{~g})$. The latencies of pawlicking reactions of mice placed on a hot plate at $55 \pm 0.1^{\circ} \mathrm{C}$ were determined. Each mouse was tested only once at $30 \mathrm{~min}$ after subcutaneous administration of ciramadol or physiological saline.

The bradykinin-induced flexor reflex test was carried out on conscious male SpragueDawley rats (160-260 g) according to the methods described by Satoh et al. (3). Bradykinin (2-4 $\mu \mathrm{g}$ in $0.2 \mathrm{ml}$ physiological saline) was injected into the right common iliac artery at intervals of 10 or $20 \mathrm{~min}$ through a cannula implanted retrogradely into the left common iliac artery from the left femoral artery. Bradykinin-induced flexor reflexes of the right hind limb were recorded on a kymograph. When, after administration of ciramadol, the magnitude of the reflexes was less than $25 \%$ of the smallest value among control trials, the effect was regarded as analgesic. The ED50 values and $95 \%$ confidence limits were determined according to the method of Litchfield and Wilcoxon (9).

For injection of ciramadol into the lumbar subarachnoid space (intrathecal injection). a polvethylene tube $(13 \mathrm{~cm}$ length and $0.5 \mathrm{~mm}$ o.d.) was inserted through a puncture in the atlanto-occipital membrane so that the tip rested on the dorsal aspect of the rostral margin of the lumbar enlargement and fixed to the skull with dental cement. Such an operation was done under ether anesthesia immediately before cannulation for bradykinin injection. Ciramadol was dissolved in physiological saline and injected intrathecally in a volume of $10 \mathrm{kl}$. 
Microinjection of ciramadol into the NRPG-NRGC was done according to the method described by Akaike et al. (8). Ciramadol dissolved in physiological saline at various concentrations was injected into the NRPG-NRGC in a volume of $0.5 \mu$ from an injection cannula introduced through a guide cannula which had been unilaterally implanted under pentobarbita: anesthesia one week before experiments so that the tip of the guide cannula was located $4 \mathrm{~mm}$ above the NRPG-NRGC. At the end of each experiment, the microinjection site was histologically verified to be in the NRPG. $N R G C$. Each rat was given only one dose of ciramadol, subcutaneously, intrathecally or into the NRPG-NRGC.

Subcutaneous administration of ciradadol did not produce any detectable effect with the tail-pinch tests in mice at doses of 5, 10, 20, 50 and $100 \mathrm{mg} / \mathrm{kg}$ (10 mice per each dose) and in rats at doses of 5 and $50 \mathrm{mg} / \mathrm{kg}$ ( 3 and 4 rats, respectively). Furthermore, ciramadol in subcutaneous doses of 5,10 and $50 \mathrm{mg} / \mathrm{kg}$ did not significantly influence latencies of paw-licking and jumping reactions (10 mice per each dose) in the hot-plate test

on the other hand, the bradykinin-induced flexor reflexes of rats were suppressed by subcutaneous ciramadol in a dose-dependent manner at doses of $0.5,1,2$ and $4 \mathrm{mg} / \mathrm{kg}$. Such an analgesic effect appeared within 15 min after administration of the drug and lasted for $70 \mathrm{~min}$ or more. The ED50 value (95\% confidence limits) was $1.18(0.63-2.23)$ $\mathrm{mg} / \mathrm{kg}$. The suppressive effect of ciramadol was antagonized by naloxone $(0.1 \mathrm{mg} / \mathrm{kg}$. i.v.) given $30 \mathrm{~min}$ after ciramadol administration (Fig. 1).

Intrathecal injection of ciramadol in doses of $0.1,0.5$ and $1 \mathrm{\mu g} / \mathrm{rat}$ produced a dosedependent analgesic effect in the bradykinininduced flexor reflex test. The ED50 value was $0.32(0.15-0.63) \mathrm{kg} / \mathrm{rat}$. Such an effect appeared within 5 min after the injection and
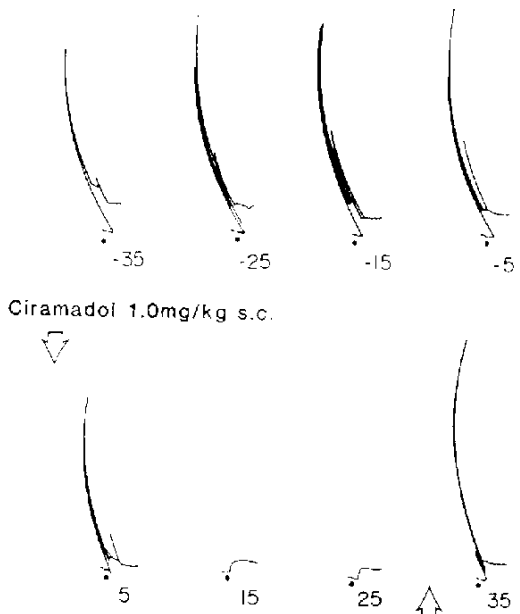

Bik2ugi.o.

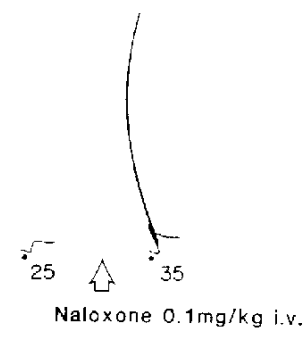

Fig. 1. A suppressive effect of ciramadol subcutaneously administered on bradykinin-induced flexor reflexes in a rat and reversal of the inhibition by naloxone. Minus sigus indicate time before ciramadol administration.

lasted for 60 min or more in 5 out of 10 rats in which the analgesic effects were produced by intrathecal ciramadol. Ciramadol microinjected into the NRPG-NRGC produced a dose-dependent suppression of bradykinininduced flexor reflexes in doses of 1,2 and $5 \mu \mathrm{g} / \mathrm{rat}$. The ED50 value was $1.5(0.84-2.7)$ / $/ \mathrm{g} / \mathrm{rat}$. The suppressive effects appeared within 5 min after the microinjections and recovered within $60 \mathrm{~min}$ in 7 out of 10 rats in which the effects were produced by microinjections of the drug into the NRPG-NRGC. Longer lasting anaigesic effects observed in four rats injected intrathecally and in three rats microinjected into the NRPG-NRGC were reversed by naloxone $(0.1 \mathrm{mg} / \mathrm{kg}$, i.v.) given 80 or 100 min after ciramadol applications (Fig. 2)

Ciramadol did not elicit any motor impairment at the doses used in the bradykinininduced flexor reflex tests, suggesting that the suppressive effects of ciramadol on the bradykinin-induced flexor reflexes were hardly due to inhibitory effects of the drug on 
A

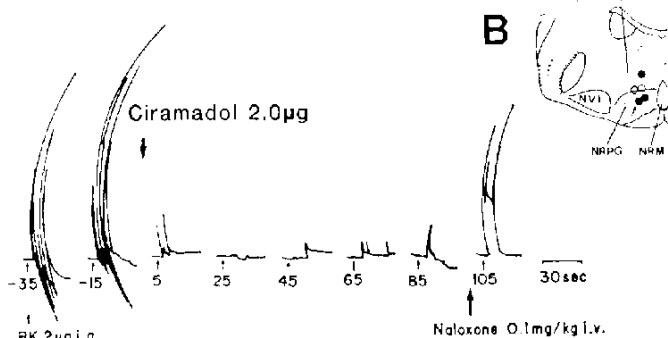

C

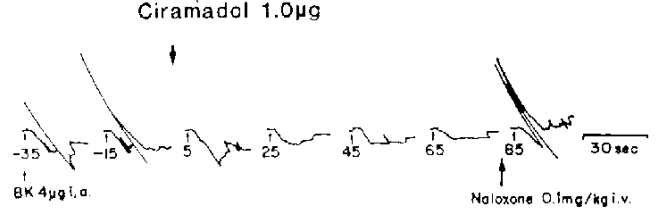

Fig. 2. Examples of inhibitory offects of ciramadol microinjected into the NRPG-NRGC (A) and applicd into the !umbar subarachnoid space (C) on the bradykinin-induced flexor reflexes in rats and antagonism to the inhibition by naloxone. (B) stows microinjection sites in the NRPG-NRGC of rats. Filled marks, but not open marks, indicate the microinjection sites where ciramadol (2 $\%$ g/rat) produced analgesia. A filled circle marked with a small arrow shows a microinjection site in an experiment from which the data represented in (A) wore obtained. Minus signs indicate time before ciramadol application.

the motor systems.

The present experiments demonstrated that an analgesic effect of ciramadol administered systemically was detected with the bradykinin-induced flexor reflex test, but not with the tail-pinch and hot-plate tests. The analgesic effect was antagonized by naloxone (0.1 mg/kg, i.v.), indicating that ciramadol acted through specific opioid receptors. Such a pharmacological profile of ciramadol is similar to that of pentazocine. Judging from the ED50 values of ciramadol and pentazocine (4) in the bradykinin-induced flexor reflex test $(1.18$ and $1.45 \mathrm{mg} / \mathrm{kg}$. s.c. respectively), the analgesic potencies of both drugs are approx. equivalent. Such results fairly correspond to clinical data that the analgesic potency of ciramadol to postoperative pain was nearly equal to that of pentazocine (2).

Micro-applications of ciramadol to the lumbar subarachnoid space and NRPGNRGC produced dose-dependent analgesic effects in the bradykinin-induced flexor reflex test. The potency in the former case was 4.7 times more than that in the latter case, suggesting that the action of ciramadol on the spinal cord more greatly contributes to the production of analgesia by the drug than that on the supraspinal structures like NRPGNRGC. On the other hand, in the tail-pinch test, the analgesic potency of morphine applied to the lumbar subarachnoid space has been shown to be 13 times less than that of the drug microinjected into the NRPGNRGC (6). Moreover, the analgesic effect of pentazocine in the bradykinin-induced flexor reflex test was much less in spinal rats than in intact rats (4). These observations suggest the main site of analgesic action of ciramadol is different from that of morphine and pentazocine; the former is at the spinal level, but the latter is in the supraspinal structures such as the NRPG-NRGC.

\section{References}

1) Yardley, J.P., Fletcher, H., III and Russell, P.B.: A potent benzylamine analgesic: $(-) \operatorname{cis}-2(\alpha-$ dimethylamino-m-hydroxybenzyl)cyclohexanol. Experientia 34, 1124-1125 (1978)

2) Camu, F:: Double-blind comparison of the analgesic response to oral ciramadol (Wy$15,705)$ and pentazocine in post-operative pain. Eur. J. Clin. Pharmacol. 19, 259-262 (1981)

3) Satoh, M., Kawajiri, S., Shishido, K., Yamamoto, M. and Takagi, H.: Bradykinin-induced flexor reflex of rat hind-limb for evaluating various analgesic drugs. J. Pharm. Pharmacol. 31, 184-186 (1979)

4) Satoh, M., Kawajiri, S., Yamamoto, M., Foong, F.W. and Masuda, C.: Analgesic action of cyclazocine: Blocking nociceptive responses induced by intra-arterial bradykinin-injection ard tooth pulp stimulation. Arch. Int. Pharmacodyn. Thor. 241, 300-306 (1979)

5) Akaike, A., Shibata, T., Satoh, M. and Takagi, H.: Analgesia induced by microinjection of morphine into, and electrical stimulation of, the 
nucleus reticularis paragigantocellularis of ral medulla oblongata. Neuropharmacology 17. $775-778$ (1978)

6) Kuraishi, Y., Satoh, M., Harada, Y., Akaike, A., Shibata, T. and Takagi, H.: Analgesic action of intrathecal and intracerebral $\beta$-endorphin in rats: Comparison with morphine. Eur. J. Pharmacol. 67, 143-146 (1980)

7) Takagi, H., Inukai, T. and Nakama, M.: A modification of Haffner's method for testing analgesics. Japan. J. Phamacol. 16, 287-294
(1966)

8) Akaike, A., Satoh, M. and Takagi, H.: A new device for microinjection of drugs into the lower brain stem of conscious rats: Studies on site of action of morphine. J. Pharmacol. Methods 2, 371-378 (1979)

9) Litchfield, J.T., Jr. and Wilcoxon, F.: A simplified method of evaluating dose-effect experiments. J. Pharmacol. Exp. Ther. 96, 99$113(1949)$ 